\title{
Deficits of perceived spatial separation induced prepulse inhibition in patients with schizophrenia: relationships to symptoms and neurocognition
}

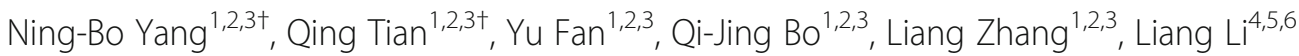
and Chuan-Yue Wang ${ }^{1,2,3^{*}}$

\begin{abstract}
Background: Prepulse inhibition (PPI) and attention were impaired, which may cause psychotic symptoms and (or) hinder the cognitive functions in schizophrenia. However, due to the measurement methods of PPI, findings about the relationship between PPI and clinical symptoms, cognitive performances have been equivocal.

Methods: Seventy-five schizophrenia patients (SZ) and 50 healthy controls (HC) were assessed in a modified acoustic PPI paradigm, named perceived spatial separation-induced PPI (PSS-PPI), compared to perceived spatial co-location PPI (PSC-PPI) with inter-stimulus interval (ISI) of 120 ms. Repeatable Battery for the Assessment of Neuropsychological Status and the Stroop Color-Word Test were administered to all subjects.
\end{abstract}

Results: Significant decrease in the modified PPI was found in the patients as compared to the controls, and effect sizes (Cohen'd) for patients vs. HCs \% PPI levels achieved a significant level (PSC-PPI $d=0.84$, PSS-PPI $d=1.27$ ). A logistic regression model based on PSS-PPI significantly represented the diagnostic grouping $\left(X^{2}=29.3 ; p<0.001\right)$, with $85.2 \%$ area under ROC curve in predicting group membership.

In addition, patients exhibited deficits in neurocognition. Among patients of "non-remission", after controlling for gender, age, education, duration, recurrence times, onset age, cigarettes per day and chlorpromazine equivalent dosage, PSS-PPI levels were associated with positive and negative symptoms, PANSS total and thought disorder (P1, P6, P7, N5, N7, G9). In multiple linear regression analyses, male and higher attention scores contributed to better PSC-PPI and PSS-PPI in controls group, while larger amount of smoke and longer word-color interfere time contributed to poor PSS-PPI. In patients' group, higher education and attention scores contributed to better PSS-PPI, while repeated relapse contributed to poor PSS-PPI.

Conclusions: The acoustic perceived spatial separation-induced PPIs may bring to light the psychopathological symptoms, especially for thought disorder, and the mechanism(s) of the novel PPI paradigm was associated with attention function.

Keywords: Schizophrenia, Prepulse inhibition, Perceived spatial separation, Clinical symptom, Thought disorder, Cognitive function, Attentional function

\footnotetext{
*Correspondence: wang_cy@ccmu.edu.cn

${ }^{\dagger}$ Equal contributors

'Department of Psychiatry, Beijing Anding Hospital, Capital Medical

University, No.5 Ankang Lane, Dewai Avenue, Xicheng District, Beijing

100088, China

${ }^{2}$ Beijing Key Laboratory of Mental Disorders, No.5 Ankang Lane, Dewai

Avenue, Xicheng District, Beijing 100088, China

Full list of author information is available at the end of the article
}

C The Author(s). 2017 Open Access This article is distributed under the terms of the Creative Commons Attribution 4.0 International License (http://creativecommons.org/licenses/by/4.0/), which permits unrestricted use, distribution, and reproduction in any medium, provided you give appropriate credit to the original author(s) and the source, provide a link to the Creative Commons license, and indicate if changes were made. The Creative Commons Public Domain Dedication waiver (http://creativecommons.org/publicdomain/zero/1.0/) applies to the data made available in this article, unless otherwise stated. 


\section{Background}

Abnormalities of information-processing are viewed as core elements of the cognitive deficits and emotion disturbances that characterize schizophrenia $[1,2]$. A major feature of information processing deficits in schizophrenic patients is deficient sensorimotor gating, which can be examined operational via the use of prepulse inhibition (PPI) and P50 [3, 4].

Prepulse inhibition occurs when a non-startling stimulus (the prepulse) results in a reduced startle response to a subsequent startling stimulus [5]. Recently, PPI has been shown to be reduced in schizophrenic patients as well as in unaffected relatives [6], and be considered a promising candidate endophenotype for schizophrenia $[7,8]$.

Most previous studies used "passive" paradigm to investigate prepulse inhibition, while, more and more evidence has shown that individuals who direct their attention to the prepulse signal show enhanced PPI [9-11]. Importantly, paying attention to a prepulse that is presented shortly before the startle stimulus enhances PPI in normal people, but not in schizophrenia patients $[12,13]$. In the active paradigm (also known as the "attention to prepulse" paradigm), most studies have demonstrated that the attentional modulation effect on PPI occurs with a lead time of $120 \mathrm{~ms}$, and the same effect is not seen if the lead time is shorter $(60 \mathrm{~ms})$ or longer $(240 \mathrm{~ms})[13,14]$. In addition, prepulse-to-pulse intervals of 30-240 ms are typically utilized in human PPI experiments, with maximal amplitude inhibition generally occurring within intervals of approximately $120 \mathrm{~ms}$ [15]. Moreover, when a noise masker is presented in the active paradigm, a precedence-effectbased perceived separation is introduced between the noise masker and the prepulse, and this introduction leads to further enhancement of PPI in rats [16].

The question can then be asked: what is the precedence effect? In a reverberant environment, listeners have the ability to integrate direct sound waves with the reflections from a sound source: attributes of the delayed and correlated reflection are captured by the direct wave, leading to a single fused image whose perceived point of origin is around the location of the leading source [17]. In humans, when both the target sound and the masker are presented by each of the two spatially separated loudspeakers with an inter-loudspeaker delay of $3 \mathrm{~ms}$, recognizing the target speech under the condition of perceived target-masker spatial separation (when the leading loudspeaker was different between target and masker) is significantly better than that under the condition of perceived co-location (when the leading loudspeaker was the same for both target and masker) [18]. The enhancement of recognition is caused by higher-order processes including the improvement of selective attention to the target.

The perceived spatial separation paradigm based on the precedence effect between the target and masking signals has been previously shown to promote listener's selective spatial attention to the target signal without changing the signal spectrum, intensity, and/or density of the audio-image. Ultimately, this improves recognition of the target signal $[19,20]$. This modified PPI paradigm has been used in many animal experiments, and its effect, validity and reliability have all been reliably demonstrated [21].

The evidences that deficit in prepulse inhibition contributes to symptomatic, cognitive impairment in schizophrenia are less consistent. Studies report weak or no significant correlations between PPI and psychiatric symptom severity in schizophrenia [22-25]. Some evidence associates deficient PPI to the core schizophrenia trait, rather than symptoms, or cognitive and social functional impairment [26, 27]. Others report deficient PPI only in significant symptomatic patients [28-30]. In addition, schizophrenia patients showed impairment not only in baseline PPI but also in the attentional modulation of PPI. More importantly, the deficit of PPI in schizophrenia was more related with the symptom severity when the prepulse was attended, but not when ignored [12].

Attentional impairments may disrupt many other cognitive functions and meta-analysis studies suggest moderate-to-severe attentional impairments in schizophrenic patients $[31,32]$. In line with that, recent studies in rat-based model of schizophrenia-relevant symptom have shown that PPI is a positive predictor of spatial working memory and latent inhibition [33, 34]. Furthermore, previous studies have also shown dysfunctions in selective spatial attention in schizophrenia [35]. Given this, we hypothesized that the perceived spatial separation paradigm of PPI would be a more robust impairment index and might be a more sensitive measure to specific cognitive variables that are important in schizophrenia.

In the present study, a modified PPI was conducted in a sample of Chinese schizophrenia patients to test the hypothesis that PPI deficits in patients with schizophrenia are significantly related to measures of symptom severity, neurocognitive performance. This study might provide a novel PPI paradigm for clinical research, as well as further illustration of the novel PPI paradigm.

\section{Methods \\ Study population}

Eighty-seven patients and 60 healthy controls were enrolled with right-handed and did not show any puretone hearing impairment at the frequency of $1000 \mathrm{~Hz}$ in each ear. Diagnosis of schizophrenia was confirmed by administering the Structured Clinical Interview for DSM-IV (SCID) by research psychiatrists. Enrollment criteria for schizophrenia patients included: 1) clinically stable subjects without neurologic diseases or known 
history of head trauma, 2) no electroconvulsive therapy within the past 6 months, and 3) no history of drug or substance abuse and dependence (except tobacco). Patients were excluded if they had unstable medical conditions or IQ below 70. All patients received antipsychotic medications as usual during the period of this study.

The control group included mentally stable, healthy individuals. All control subjects answered semi-structured questions to exclude participants with a history of drug or alcohol abuse or dependence within 6 months before testing, major head trauma involving loss of consciousness for more than $5 \mathrm{~min}$, epilepsy or other neurological dysfunction or first-degree family history of psychosis. Following a detailed description of the procedures involved and overall aims of this study, all participants provided informed written consent. This study was reviewed and approved by the Independent Ethics Committee (IEC) of the Beijing Anding Hospital, Capital Medical University, China.

\section{Demographic details and clinical characteristics}

Basic socio-demographic characteristics and clinical data were collected by a questionnaire specifically designed for this study. The psychopathology of each patients was evaluated by the Positive and Negative Syndrome Scale (PANSS, Chinese version) [36]. Patients and healthy controls were additionally assessed on Repeatable Battery for the Assessment of Neuropsychological Status (RBANS, Chinese version) [37] and the traditional card version of the Stroop Color-Word Test (Chinese version) [38]. There was good agreement on ratings performed by physicians and trained psychologists (Cohen's $=0.80$ ).

\section{Startle response measurements}

Each subject sat comfortably in a recliner chair in a sound-attenuated room. Two $4 \mathrm{~mm} \mathrm{Ag} / \mathrm{AgCl}$ electrodes were positioned below and lateral to the right eye, directly over the orbicularis oculi. A ground electrode was then placed behind the right ear. Electrode resistances were $<5 \mathrm{k} \Omega$. The eye blink component of the acoustic startle system was evaluated using a human electromyography (EMG) startle reflex system (EMG XEYE human Startle Reflex, Tian Ming Hong Yuan Instruments Company, Beijing, China). This system recorded 300, 1-ms epochs for digitization and analysis, beginning with the startle stimulus onset. In addition, EMG activity was band-pass filtered $(100-1000 \mathrm{~Hz})$ and amplified by 10,000 . Acoustic startle stimuli were presented binaurally through two headphones (HD 265 linear, SENNHEISER, Germany) (Fig. 1a). Acoustic signals were calibrated by a sound-level meter (AUDit and System 824, Larson Davis, USA).

The test began with a 2-min adaptation period of $60 \mathrm{~dB}$ SPL broadband background noise, during which 4 startling sounds (broadband white noise, $40 \mathrm{~ms}$, $104 \mathrm{~dB}$ SPL) were presented. Next, we conducted 2-blocks of PPI testing. In each block, 7 trials contained the startling
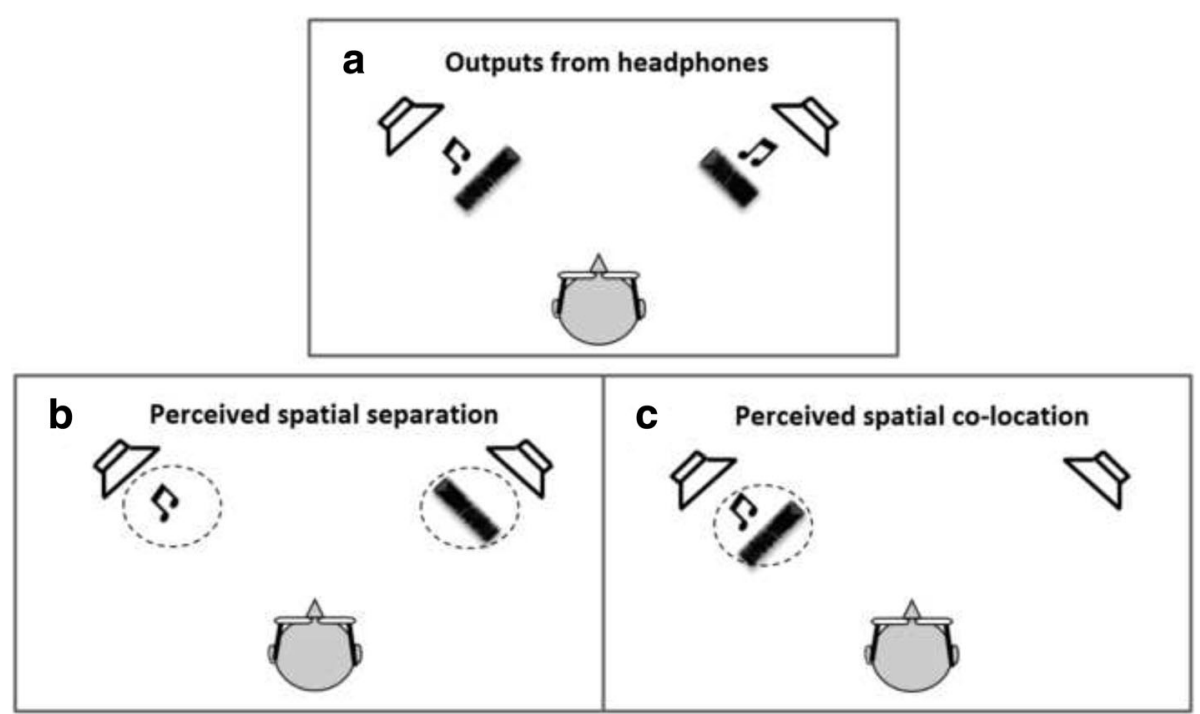

Fig. 1 Diagrams showing the physical (Panel a) and perceived (Panels $\mathbf{b}$ and $\mathbf{c}$ ) spatial relationship between the prepulse (the music note) and the noise masker (noise waveform). (Panel a) Both the prepulse and the noise masker were delivered by each of the two horizontally separated headphones. (Panel b) The onset of the prepulse delivered by the left headphone led that from the right headphone by $3 \mathrm{~ms}$, and the image of the prepulse (music note in the circle) was perceived as coming from the left headphone; the onset of the masker from the right headphone led that from the left headphone by $3 \mathrm{~ms}$, and the image of the masker (noise waveform in circle) was perceived as coming from the right headphone. Thus, the prepulse and the noise masker were perceived spatially separated. (Panel c) Both the onset of the prepulse and the onset of the masker presented from the left headphone led those from the right headphone, and the image of the prepulse (music note in circle) and that of the masker (noise waveform in circle) were perceived spatially co-located 


\section{Experimental design}

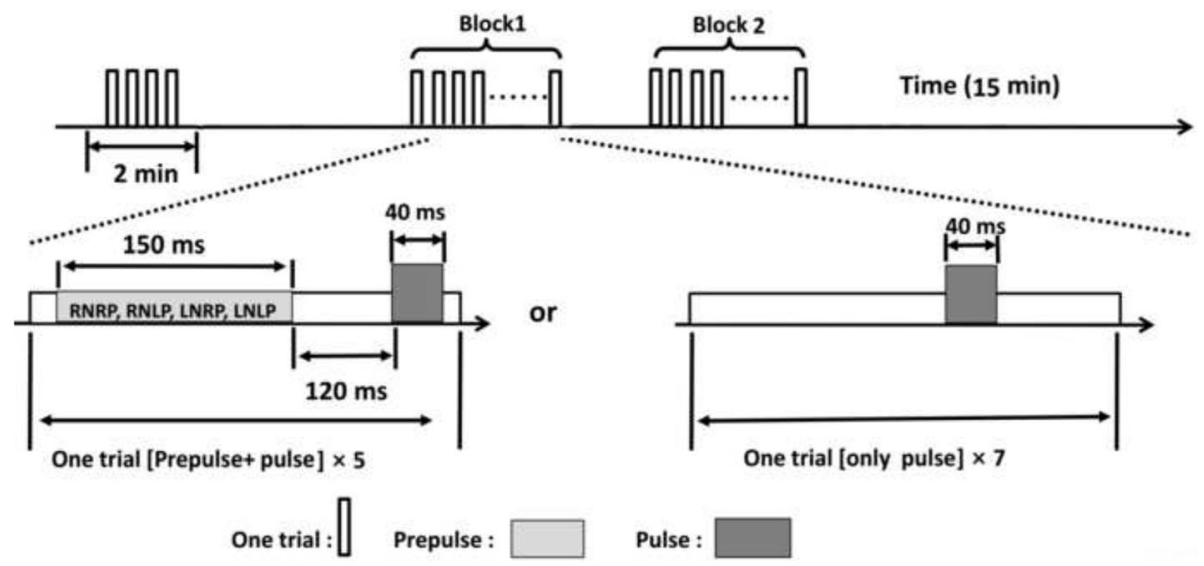

Fig. 2 Schematic illustration of the perceived spatial separation paradigm applied in this study. In a block design (7 min), a background wideband noise was continuously delivered as the masker (left leading or right leading), 7 trials contained the startling (pulse) sound alone, and 20 trials contained the prepulse (left leading or right leading) $60 \mathrm{~ms}$ or $120 \mathrm{~ms}$ preceding the startling (pulse) noise. Trials in each block were presented randomly with the inter-trial interval about 20 sNote: RNRP (RNLP): right leading masking with prepulse co-location (separation); LNLP (LNRP): left leading masking with prepulse co-location (separation)

sound alone delivered by two headphones, as well as 20 trials containing the prepulse (broadband white noise, $150 \mathrm{~ms}, 65 \mathrm{~dB}$ SPL) preceding the startling noise (120 ms between the prepulse offset and the startlingsound onset) (Fig. 2). The prepulse was presented from each headphone with the inter-loudspeaker onset delay being either $+3 \mathrm{~ms}$ (left leading) or $-3 \mathrm{~ms}$ (right leading). Due to the precedence effect, a single perceptually fused image of the prepulse would be perceived at the left loudspeaker location in the first block (when the left loudspeaker led) and at the right loudspeaker location in the second block (when the right loudspeaker led) [17]. In addition to the prepulse, background, wideband noise $(0-10 \mathrm{kHz}, 60 \mathrm{~dB}$ SPL) was continuously delivered from each of the two headphones as a masker. The interheadphone onset delay for the masker was also either +3 or $-3 \mathrm{~ms}$, leading to a perceptually-fused, continuous noise-masker image that was presented either through the left headphone in one block or through the right in the other block. Thus, there were $4(2 \times 2)$ combinations of perceived locations between the prepulse and masker images across the two experimental blocks. Two types of perceived spatial relations between the prepulse and masker were created: perceptual separation (when the prepulse and masker came from a different leading headphone, Fig. 1b) and perceptual co-location (when the prepulse and masker shared the same leading headphone, Fig. 1c). Trials in each block were presented randomly with the inter-trial interval of approximately $20 \mathrm{~s}$ (varying between $15 \mathrm{~s}$ and $25 \mathrm{~s}$ ).

Startle eyeblink responses were recorded as electromyographic activity. Each trial was visually inspected for
Table 1 Demographic and clinical characteristics for SZ patients and $\mathrm{HC}$

\begin{tabular}{lllll}
\hline Variable & $H C$ & $S Z$ & $t / X^{2}$ & $p$ \\
& $N=50$ & $N=75$ & & \\
\hline Gender (M/F) & $38 / 12$ & $54 / 21$ & 0.25 & $0.68^{\mathbf{a}}$ \\
Smoke & & & & \\
$\quad$ Ratio & $68.0 \%$ & $60.0 \%$ & 0.83 & $0.45^{\mathbf{a}}$ \\
$\quad$ Cigarettes per day & $6.6 \pm 8.8$ & $7.3 \pm 8.6$ & 0.45 & $0.65^{\mathbf{b}}$ \\
Age (year) & $42.9 \pm 8.0$ & $44.9 \pm 6.7$ & 1.57 & $0.12^{\mathbf{b}}$ \\
Education (year) & $11.6 \pm 3.2$ & $10.8 \pm 2.6$ & 0.02 & $0.89^{\mathbf{b}}$ \\
Age of onset (year) & & $24.8 \pm 6.7$ & & \\
Recurrence times & & $4.7 \pm 2.5$ & & \\
Duration (year) & & $19.5 \pm 8.4$ & & \\
Medication & & & & \\
FGA, n (\%) & & $14(18.7)$ & & \\
SGA, n (\%) & & $40(53.3)$ & & \\
FGA + SGA, $n$ (\%) & & $21(18.0)$ & & \\
CPZ(mg/day) & & $300.6 \pm 247.0$ & & \\
PANSS score & & & & \\
Total & & $62.3 \pm 13.5$ & & \\
Positive & & $12.6 \pm 4.7$ & & \\
Negative & & $19.7 \pm 6.5$ & & \\
General & & $29.9 \pm 5.7$ & & \\
\hline
\end{tabular}

Note: Data are expressed as mean $\pm S D, S D$ standard deviation, $S Z$ schizophrenia patients, $H C$ healthy controls, $C P Z$ chlorpromazine equivalent dosage

PANSS: positive and negative syndrome scale; ${ }^{\mathrm{a}}$ indicates $p$ value for chisquare test; ${ }^{b}$ indicates $p$ value for independent sample t-test. 
Table 2 Between-group differences in modified PPI

\begin{tabular}{|c|c|c|c|c|c|}
\hline \multirow[t]{2}{*}{ Variable } & $\mathrm{HC}$ & $\mathrm{SZ}$ & $t$ & $p^{a}$ & \multirow{2}{*}{$\begin{array}{l}\text { Cohen's } \\
d\end{array}$} \\
\hline & $N=50$ & $N=75$ & & & \\
\hline \multicolumn{6}{|l|}{ Startle } \\
\hline Mean $( \pm S D)$ & $50.4 \pm 21.3$ & $45.4 \pm 24.0$ & 1.18 & 0.24 & 0.22 \\
\hline Median (range) & $47.5(14.7-81.9)$ & $42.9(8.2-111.7)$ & & & \\
\hline \multicolumn{6}{|l|}{ Habituation } \\
\hline Mean $( \pm S D)$ & $14.9 \pm 31.0$ & $15.9 \pm 22.0$ & 0.24 & 0.84 & 0.04 \\
\hline Median (range) & $15.8(-13.2-44.7)$ & $16.6(-20.6-52.4)$ & & & \\
\hline \multicolumn{6}{|l|}{ PSC-PPI } \\
\hline Mean $( \pm \mathrm{SD})$ & $31.7 \pm 25.6$ & $9.4 \pm 29.3$ & 4.38 & 0.00 & 0.84 \\
\hline Median (range) & $36.2(-32.7-77.8)$ & $12.9(-5.9-70.8)$ & & & \\
\hline \multicolumn{6}{|l|}{ PSS-PPI } \\
\hline Mean $( \pm S D)$ & $50.7 \pm 29.4$ & $13.0 \pm 29.8$ & 6.97 & 0.00 & 1.27 \\
\hline Median (range) & $48.6(-6.3-91.1)$ & $17.29(-69.6-73.5)$ & & & \\
\hline
\end{tabular}

Note: Data are expressed as mean $\pm S D, S D$ standard deviation, SZ schizophrenia patients, $H C$ healthy controls, PPI prepulse inhibition, PSC-PPI perceived spatial co-location PPI, PSS-PPI perceived spatial separation PPI; ${ }^{a}$ indicates $p$ value for independent sample t-test

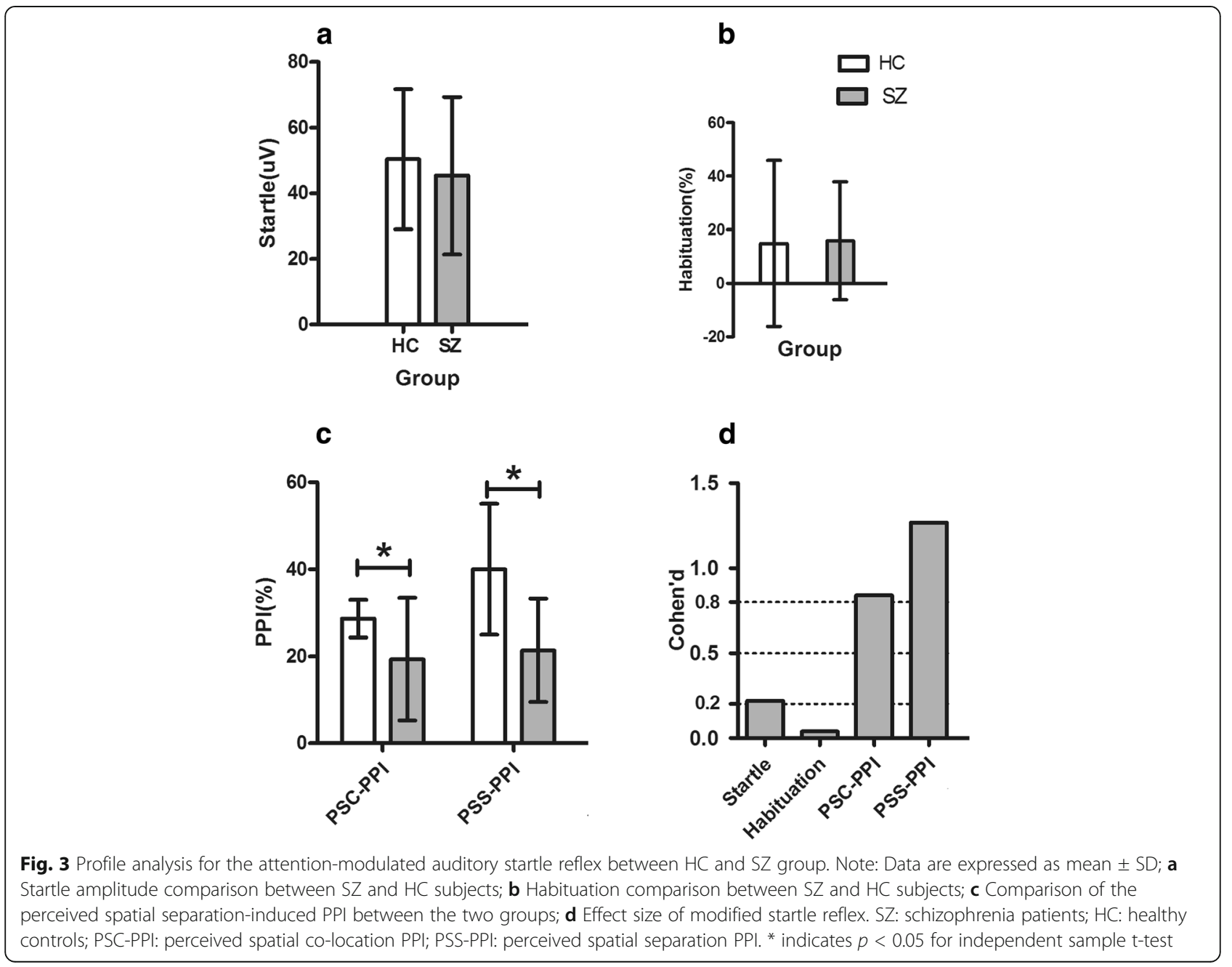


Table 3 Logistic regression model for different PPI distinguishing schizophrenia patients from healthy controls (ISI = $120 \mathrm{~ms})$

\begin{tabular}{|c|c|c|c|c|c|c|c|c|c|c|c|c|}
\hline Predictor & $x^{2}$ & $d f$ & $p$ & $O R$ & $95 \% \mathrm{Cl}$ & $R^{2}$ & Sensitivity & Specificity & Accuracy & PPV & NPV & $A \cup C$ \\
\hline PSC-PPI & 14.6 & 1 & 0.00 & 0.97 & $0.95-0.98$ & 0.17 & 75.0 & 52.0 & 72.0 & 72.7 & 70.3 & 72.0 \\
\hline PSS-PPI & 29.3 & 1 & 0.00 & 0.94 & $0.93-0.96$ & 0.46 & 87.0 & 66.0 & 78.4 & 79.3 & 76.7 & $85.2^{*}$ \\
\hline
\end{tabular}

Note: The goodness-of-fit $\left(X^{2}\right)$ and effect size indicator (Nagelkerke's $\mathrm{R}^{2}$ ) measure how well the model represents the diagnostic groupings. ISI inter-stimulus interval, PPI prepulse inhibition, PSC-PPI perceived spatial co-location PPI, PSS-PPI perceived spatial separation PPI, PPV positive predictive value, NPV negative predictive value, $A U C$ area under ROC curve; * indicates $p<0.05$ for DeLong's test

spontaneous and voluntary blinks. Trials with artifacts were excluded from analysis (total trial exclusion $<4 \%$ ). Electromyographic activity under either the perceived spatial co-location (PSC) or perceived spatial separation (PSS) conditions were recorded.

Percent habituation $(100 \times$ [average of first habituation block - average of second habituation block]/average of first habituation block) was calculated for each subject. $\mathrm{PPI} \%=100 \times(1-$ [mean magnitude on prepulse trials $/$ mean magnitude on pulse alone trials]).

\section{Statistical analysis}

Data analysis was performed by $\mathrm{R}$ Development Environment and R Studio Desktop (Open Source Edition) [39]. The normality of the distributions for continuous variables was checked using a one-sample KolmogorovSmirnov test. Comparisons between the two groups of subjects about socio-demographic characteristics and mean scores on PPI and cognitive tests were performed using independent sample t-test and chi-square tests. Binomial logistic regression was applied for discriminating patients from controls. Associations of performance on PPI tasks with socio-demographic and clinical characteristics and other neurocognitive tests were analyzed using Pearson correlation analysis if the data followed a normal distribution; otherwise, Spearman rank correlation analysis was performed. Stepwise multiple linear regression analyses were used to identify factors that were independently associated with performance on the two types of PPI. In the stepwise regression analyses, the perceived spatial co-location PPI (PSC-PPI) and perceived spatial separation PPI (PSS-PPI) scores were entered as the dependent variable, and all variables were entered as independent variables. Two tailed tests were used in all analyses with the significance level set at 0.05 .

\section{Results}

\section{Subject demographics}

A total of 22 participants (12 patients and 10 control subjects) were excluded for their failing to blink to the startling stimulus. Demographic characters as well as the medication status for the remaining participants are summarized in Table 1 . There were no significant differences in age, years of education, smoking status and gender between the two groups. Medication status revealed that patients had the following pharmacotherapy
Table 4 Between-group differences in cognitive variables

\begin{tabular}{|c|c|c|c|c|}
\hline \multirow[t]{2}{*}{ Variable } & $\mathrm{HC}$ & $\mathrm{SZ}$ & \multirow[t]{2}{*}{$t$} & \multirow[t]{2}{*}{$p^{a}$} \\
\hline & $N=50$ & $N=75$ & & \\
\hline \multicolumn{5}{|l|}{ RBANS } \\
\hline \multicolumn{5}{|l|}{ IMM } \\
\hline Mean $( \pm S D)$ & $97.9 \pm 16.3$ & $55.5 \pm 15.5$ & 14.69 & 0.00 \\
\hline Median (range) & $101.5(69-123)$ & 49(40-106) & & \\
\hline \multicolumn{5}{|l|}{ VC } \\
\hline Mean $( \pm \mathrm{SD})$ & $85.6 \pm 12.0$ & $79.7 \pm 15.9$ & 2.23 & 0.03 \\
\hline Median (range) & $87(64-121)$ & 78(50-109) & & \\
\hline \multicolumn{5}{|l|}{ LAN } \\
\hline Mean $( \pm S D)$ & $96.9 \pm 14.6$ & $77.9 \pm 12.3$ & 7.89 & 0.00 \\
\hline Median (range) & $91(78-130)$ & $76(44-105)$ & & \\
\hline \multicolumn{5}{|l|}{ ATT } \\
\hline Mean $( \pm \mathrm{SD})$ & $109.4 \pm 12.2$ & $91.8 \pm 12.2$ & 7.94 & 0.00 \\
\hline Median (range) & 109(88-135) & $91(56-138)$ & & \\
\hline \multicolumn{5}{|l|}{ DEM } \\
\hline Mean $( \pm S D)$ & $95.4 \pm 8.9$ & $65.3 \pm 18.3$ & 12.25 & 0.00 \\
\hline Median (range) & $97(77-100)$ & $64(18-100)$ & & \\
\hline \multicolumn{5}{|l|}{ TOT } \\
\hline Mean $( \pm S D)$ & $93.8 \pm 10.8$ & $66.9 \pm 12.2$ & 12.62 & 0.00 \\
\hline Median (range) & $91(75-122)$ & $65(43-100)$ & & \\
\hline \multicolumn{5}{|l|}{ Stroop Test } \\
\hline \multicolumn{5}{|l|}{ INT-C } \\
\hline Mean $( \pm S D)$ & $4.2 \pm 3.8$ & $7.6 \pm 6.9$ & 2.10 & 0.04 \\
\hline Median (range) & $5.1(-2.4-32.0)$ & $1.6(-11.0-39.3)$ & & \\
\hline \multicolumn{5}{|l|}{ INT-W } \\
\hline Mean $( \pm S D)$ & $15.3 \pm 11.6$ & $24.0 \pm 13.0$ & 4.14 & 0.00 \\
\hline Median (range) & $16.1(-18.3-49.0)$ & $22.3(-12.4-63.4)$ & & \\
\hline
\end{tabular}

Note: Data are expressed as mean $\pm S D, S D$ standard deviation, $S Z$ schizophrenia patients, $H C$ healthy controls, IMM immediate memory score, VC visuospatial/constructional score, $L A N$ language score, $A T T$ attention score, $D E M$ delayed memory score, TOT total composite score, INT-C color interference time, INT-W word interference time. ${ }^{a}$ indicates $p$ value for independent sample t-test 
a

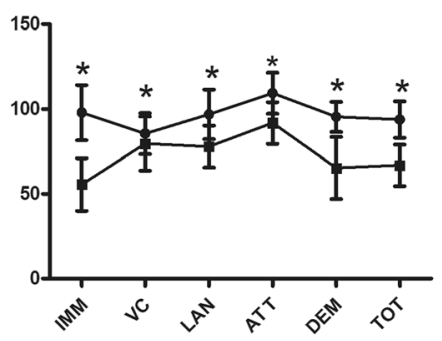

b

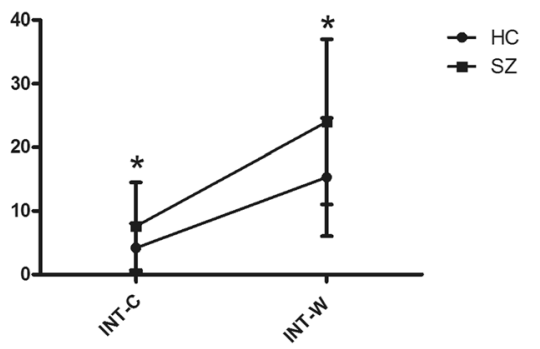

Fig. 4 Profile analysis for cognitive domains of SZ patients and HC. Note: Data are expressed as mean \pm SD. SZ: schizophrenia patients; HC: healthy controls. a RBAN comparison, IMM: immediate memory score; VC: visuospatial/constructional score, LAN: language score; ATT: attention score; DEM: delayed memory score; TOT: total cognitive functional score. b Comparison of Stroop task, INT-C: color interference time; INT-W: word interference time. ${ }^{*}$ indicates $p<0.05$ for independent sample t-test

regimens: typical antipsychotics:18.7\% $(n=14)$; atypical antipsychotics: $53.3 \%(n=40)$; and combination: $18 \%$ $(n=21)$, respectively.

\section{Group differences in modified startle reflex and cognitive functioning}

Results from between-group differences on attention modulated auditory startle reflex are shown in Table 2 (Fig. 3.) Startle magnitude and habituation revealed no differences across groups. In addition, we detected significant differences between healthy control and patients for PSC-PPI and PSS-PPI. Effect sizes of the two PPI values were all large (Cohen's d: PSC-PPI $=0.84$, PSS-PPI $=1.27$ ). The main effect of perceived spatial separation in relation to PPI was significant in healthy controls $(t=-10.57, p<0.01)$, but not in schizophrenics $(t=-0.47, p=0.64)$.

The univariate logistic regression was used to generate models that maximally separated schizophrenia patients and healthy controls. Several parameters from Table 3 were used to evaluate the model. The goodness-of-fit test (model $X^{2}:$ 29.3), and effect size estimate (Nagelkerke's $R^{2}$ : 0.46) all indicated the PSS-PPI model's greater appropriateness. The AUC of PSS-PPI obtained boosts from $72 \%$ to $85.2 \%$ for statistical significances comparing to that of PSC-PPI.

Between-group differences on cognitive variables are shown in Table 4 (Fig. 4). Patients showed significantly poorer performance than healthy controls on all cognitive tests (all values were significant at $p<0.05$ ).

\section{Correlation between PPI and symptoms and neurocognitions}

Table 5 presents the relationships between PPI and sociodemographic variables, other cognitive tests, and clinical variables. In the $\mathrm{HC}$ group, gender, higher scores on the attention score (ATT) and total composite score (TOT) were significantly associated with better PPI performance, and higher color interference time (INT-C)
Table 5 Correlation between modified PPI and demographic, clinical characteristics and neurocognition tasks in patients and controls

\begin{tabular}{|c|c|c|c|c|c|c|}
\hline \multirow[t]{2}{*}{ Variables } & \multicolumn{3}{|l|}{$\mathrm{HC}$} & \multicolumn{3}{|l|}{$\mathrm{SZ}$} \\
\hline & startle & PSC-PPI & PSS-PPI & startle & PSC-PPI & PSS-PPI \\
\hline Gender & 0.19 & $0.38^{*}$ & $0.39 *$ & -0.15 & -0.23 & -0.17 \\
\hline Age & 0.02 & 0.25 & 0.21 & 0.11 & 0.09 & 0.11 \\
\hline Education & -0.01 & 0.11 & -0.11 & -0.08 & 0.05 & 0.08 \\
\hline Cigarettes per day & -0.03 & -0.06 & -0.03 & -0.13 & -0.15 & -0.06 \\
\hline Duration & & & & 0.09 & 0.14 & 0.13 \\
\hline Recurrence & & & & 0.13 & -0.13 & -0.06 \\
\hline Onset age & & & & -0.10 & -0.01 & -0.08 \\
\hline CPZe & & & & -0.07 & -0.06 & -0.10 \\
\hline PANSS Positive & & & & -0.13 & -0.16 & -0.15 \\
\hline PANSS Negative & & & & -0.13 & -0.05 & -0.09 \\
\hline PANSS General & & & & -0.03 & -0.20 & -0.21 \\
\hline PANSS Total & & & & -0.11 & -0.15 & -0.18 \\
\hline IMM & 0.16 & 0.22 & 0.06 & -0.14 & 0.20 & 0.12 \\
\hline VC & 0.07 & 0.15 & 0.13 & -0.06 & 0.05 & -0.12 \\
\hline LAN & 0.11 & 0.27 & 0.14 & 0.07 & 0.06 & 0.09 \\
\hline ATT & 0.11 & $0.29^{*}$ & $0.28^{*}$ & -0.03 & 0.14 & 0.18 \\
\hline DEM & -0.11 & 0.03 & -0.17 & -0.04 & -0.04 & -0.15 \\
\hline TOT & 0.14 & $0.28^{*}$ & $0.31^{*}$ & -0.01 & 0.08 & -0.06 \\
\hline INT-C & $0.51^{*}$ & 0.15 & 0.12 & -0.13 & 0.04 & 0.02 \\
\hline INT-W & -0.05 & -0.15 & $-0.29^{*}$ & -0.02 & 0.10 & 0.12 \\
\hline
\end{tabular}

Note: $S Z$ schizophrenia patients, $H C$ healthy controls, $P P I$ prepulse inhibition, PSC-PPI perceived spatial co-location PPI, PSS-PPI perceived spatial separation PPI. CPZe: neuroleptic chlorpromazine-equivalent dosage. PANSS: positive and negative syndrome scale, IMM immediate memory score, VC visuospatial/constructional score, LAN language score, ATT attention score, DEM delayed memory score, TOT total composite score, INT-C color interference time, INT-W word interference time; * $p<0.05$ 
scores were associated with reflex startle, whereas less word interference time (INT-W) associated with better PSS-PPI performance. No variable was associated with any PPI tasks in patients except PANSS General negatively correlated with PSS-PPI.

In order to further discover the correlation between PPI and the symptoms severity of schizophrenia, we performed Pearson's analysis using all potential confounding variables (age, gender, education, duration, recurrence times, onset, smoke amount and drug) as covariates [40]. We did not observe any significant association between the mean PPI and PANSS scores for all 75 patients and patients whose symptoms were classed as "remission" (total PANSS score $<60$ ). However, in patients who were "non-remission" (total PANSS score $\geq 60$ ) [41], we observed a significant correlation between the PSC-PPI, PSS-PPI with P1, P6, P7, PANSS Positive, N5, N7, G9 and PANSS Total, as well as a significant correlation between the PSS-PPI with PANSS Negative (see Table 6).

Table 7 shows the independent correlates of performance on PSC-PPI and PSS-PPI in healthy controls and patients. In the healthy group, male and higher ATT scores contributed to better PSC-PPI and PSS-PPI, while high nicotine dependent and longer INT-W contributed to poorer PSS-PPI performance. In patients' group, ATT and TOT scores accounted for $9 \%$ of the variation in PSC-PPI, and did not reach statistical significance. But higher education levels, ATT and TOT scores contributed to PSS-PPI, and recurrent episodes contributed to poorer PSS-PPI.

\section{Discussion}

To our knowledge, this is the first study employing a completely new PPI paradigm in a large cohort of Chinese schizophrenia patients to demonstrate reduced PPI and poor cognitive function. Moreover, there was a statistically significant deficit of PPI in patients compared with healthy controls and the effect sizes were large. Among patients with significant symptoms, the PPI deficits were negatively related to positive symptoms and thought disorders. Correlational and stepwise regression analyses further indicated that the underlying mechanisms of the new PPI were associated with attention modulation.

Most studies using "passive" paradigm showed PPI deficit at short lead intervals $(\leq 60 \mathrm{~ms})$, which relies mainly on automatic mechanisms [26]. Meanwhile, the "instructed" or active PPI deficits which can be manipulated volitionally were found in longer ISI condition [42], and the ISI $120 \mathrm{~ms}$ was the point that stimulus discrimination (prepulse and startle stimulus) and further attentional allocation occurred [43]. In our experiment, the perceived spatial co-location paradigm (PSC) of PPI in our study is like that of the "attention-to-prepulse"
Table 6 Correlation coefficients between PPI and symptoms in patients (PANSS Total $\geq 60$, Pearson's $r, n=35, d f=25$ )

\begin{tabular}{|c|c|c|c|}
\hline Variable & Startle & PSC-PPI & $\overline{P S S-P P I}$ \\
\hline$\overline{P 1}$ & -0.20 & $-0.39^{*}$ & $-0.52^{*}$ \\
\hline P2 & 0.02 & -0.19 & -0.31 \\
\hline P3 & -0.09 & -0.12 & -0.17 \\
\hline P4 & 0.16 & -0.29 & -0.34 \\
\hline P5 & 0.05 & -0.20 & -0.24 \\
\hline P6 & -0.18 & $-0.35^{*}$ & $-0.44^{*}$ \\
\hline P7 & -0.01 & $-0.53^{*}$ & $-0.53^{*}$ \\
\hline PANSS Positive & -0.07 & $-0.37^{*}$ & $-0.47^{*}$ \\
\hline N1 & 0.06 & -0.19 & -0.31 \\
\hline N2 & 0.11 & -0.07 & -0.27 \\
\hline N3 & 0.05 & -0.17 & -0.28 \\
\hline N4 & -0.04 & -0.85 & -0.21 \\
\hline N5 & -0.05 & $-0.44^{*}$ & $-0.52^{*}$ \\
\hline N6 & -0.02 & -0.15 & -0.30 \\
\hline N7 & -0.10 & $-0.40^{*}$ & $-0.50^{*}$ \\
\hline PANSS Negative & -0.04 & -0.27 & $-0.41^{*}$ \\
\hline G1 & 0.13 & -0.21 & -0.15 \\
\hline G2 & 0.25 & -0.21 & -0.21 \\
\hline G3 & 0.12 & -0.33 & -0.32 \\
\hline G4 & 0.13 & -0.24 & -0.32 \\
\hline G5 & 0.23 & -0.11 & -0.18 \\
\hline G6 & -0.21 & -0.27 & -0.23 \\
\hline G7 & -0.30 & -0.21 & -0.17 \\
\hline G8 & 0.15 & -0.19 & -0.28 \\
\hline G9 & -0.25 & $-0.41^{*}$ & $-0.49^{*}$ \\
\hline G10 & -0.13 & -0.24 & -0.08 \\
\hline G11 & 0.33 & 0.08 & -0.23 \\
\hline G12 & -0.17 & 0.09 & -0.17 \\
\hline G13 & -0.24 & -0.22 & -0.13 \\
\hline G14 & 0.18 & -0.14 & -0.11 \\
\hline G15 & 0.26 & -0.13 & -0.05 \\
\hline G16 & $-0.57^{*}$ & -0.05 & 0.12 \\
\hline PANSS General & -0.02 & -0.35 & -0.24 \\
\hline PANSS Total & -0.02 & $-0.43^{*}$ & $-0.54^{*}$ \\
\hline
\end{tabular}

Note: PPI prepulse inhibition, PSC-PPI perceived spatial co-location PPI, PSS-PPI, perceived spatial separation PPI. PANSS positive and negative syndrome scale. The control factors were gender, age, education, duration, recurrence times, onset age, cigarettes per day and neuroleptic chlorpromazine-equivalent dosage. No correlation was found between PPI and symptoms in total patients or in patients (PANSS Total $<60$ ). ${ }^{*} p<0.05$

active paradigm, which employed subjective attention, however, the perceived spatial separation (PSS) paradigm involved not only subjective attention but also objective selective attention.

Previously published data confirmed that directing attention to the prepulse signal could enhance PPI [11, 44], and 
Table 7 Results of stepwise multiple regression analysis

\begin{tabular}{|c|c|c|c|c|c|}
\hline PPI task & Predictor & Beta & S.E. & $t$ & $p$ \\
\hline \multicolumn{6}{|l|}{$\mathrm{HC}(n=50)$} \\
\hline PSC-PPI & Gender & 26.00 & 7.41 & 3.51 & 0.00 \\
\hline Adjusted $R^{2}=0.28$ & $A T T$ & 0.56 & 0.20 & 2.79 & 0.01 \\
\hline \multicolumn{6}{|l|}{$F_{(4,45)}=5.88 ; p<0.001$} \\
\hline PSS-PPI & Gender & 33.81 & 7.83 & 4.31 & 0.00 \\
\hline Adjusted $R^{2}=0.37$ & Cigarettes per day & -0.95 & 0.43 & -2.22 & 0.03 \\
\hline \multirow[t]{2}{*}{$F_{(6,43)}=5.88 ; p<0.001$} & ATT & 0.61 & 0.19 & 3.23 & 0.00 \\
\hline & INT-W & -0.77 & 0.32 & -2.38 & 0.02 \\
\hline \multicolumn{6}{|l|}{$S Z(n=75)$} \\
\hline PSC-PPI & ATT & 1.17 & 0.43 & 2.27 & 0.01 \\
\hline Adjusted $R^{2}=0.09$ & TOT & 2.04 & 0.82 & 2.49 & 0.02 \\
\hline \multicolumn{6}{|l|}{$F_{(8,66)}=1.96 ; p>0.05$} \\
\hline PSS-PPI & Education & 3.05 & 1.27 & 2.41 & 0.02 \\
\hline Adjusted $R^{2}=0.17$ & Recurrence times & -3.10 & 1.25 & -2.48 & 0.00 \\
\hline \multirow[t]{2}{*}{$F_{(8,66)}=2.85 ; p<0.05$} & $\mathrm{ATT}$ & 1.18 & 0.32 & 3.70 & 0.00 \\
\hline & ТOT & 1.86 & 0.48 & 3.86 & 0.00 \\
\hline
\end{tabular}

Note: S.E standard error, SZ Schizophrenia patients, HC healthy controls. PPI prepulse inhibition, PSC-PPI perceived spatial co-location PPI, PSS-PPI perceived spatial separation PPI. ATT attention score, TOT total composite score, INT-W word interference time

attention plays a key role in selecting relevant and ruling out irrelevant modalities, spatial locations, and task-related objects [45]. The reason for significantly enhanced PSS-PPI in controls may attribute to intact selective attention to the target stimulus, which is greatly impaired in patients [46]. So, this novel PSS-PPI paradigm which integrated measurements of sensory gating, attention and precedence effect, might achieve robust effect size for discriminating schizophrenia patients from healthy controls.

"Sensorimotor gating deficits" are hypothesized to contribute to sensory overload, interceptive stimuli and cognitive fragmentation, resulting in psychotic symptoms and cognitive deficits [47]. The results of this work indicate that the modified PPI was negatively correlated with symptom severity in group PANSS $\geq 60$, and focused on thought disorder. Previous studies have shown strong associations between PPI deficits and thought disorder and distractibility. This relationship is most apparent when a specific, highly sensitive measure of PPI (novel PSS-PPI) is used. Thought disorder has been considered a hallmark feature of schizophrenia [48]. Besides one part of the positive symptom complex, factor analytic studies of symptom ratings suggested that disorganized thought is distinct from positive symptoms such as hallucinations and delusions. Moreover, thought disorder is different from positive and negative symptoms in development and course of the illness [49]. In this study, the PPI were correlated with P1, P6, P7, N5, N7 and G9, which included not only formal thought disorder but content of thought.
Previous researches have confirmed that the "attentionto-prepulse" PPI deficiency is more associated with the symptom severity in the schizophrenia spectrum and the correlates between symptoms [12] and PPI deficits in patients with schizophrenia cannot be detected in the passive-attention PPI paradigm [26]. From a Circular Inference models standpoint [50], the mechanism of the new PPI paradigm may involve a recognition (recognition of spatial separation of target-masker) evoked top-down modulation of information processing, which greatly impaired in schizophrenia patients [51]. Therefore, the new PPI paradigm may relate far more sophisticated thought elements rather than simple perception abnormal [52].

Regression analyses indicated that the modified PPI was typically related to attention scores, no matter in healthy controls or patients, especially for PSS-PPI. Stroop test has long been taken as a measure of perceptual switching, selective attention and cognitive inhibition [53, 54]. Accordingly, in our study, less INT-W might indicate better of PSS- PPI in control subjects but not in patients. These results agreed with the study of Bitsios and Giakoumaki [55], which indicated subjects with the best attentional selection in the Stroop task may be more prone to attentional selection of the prepulse and thus more likely to present with greater startle inhibition. However, patients partly lose cognitive inhibition $[9,56]$.

When interpreting the results of this study, several limitations must be considered. First, most patients enrolled in this study were chronic schizophrenia patients and did not manifest every possible symptom [57], 
which would not permit drawing assertive conclusion for heterogeneous schizophrenia. Therefore, future studies are needed to extend to first-episode, antipsychoticnaïve schizophrenia patients and to clinical high risk to validate the effectiveness. Second, this study included a higher male to female ratio. Although, the gender was controlled as a covariate, higher PPI levels have been reported in healthy males compared to healthy females [26]. In addition, PPI values may be influenced by the changes of menstrual period within the same female subjects [58]. Third, PPI levels in our study were relatively lower than those in previous studies [40], which may be due to parameter option of our PPI paradigm. However, we still obtained sufficient PPI levels and robust effect sizes as one study [59]. Finally, the cross-sectional study design, which precluded further examination stability and mediating variables over times. Ideally, such studies should employ larger samples to scrutinize trait versus state effects, illness phase specific, and the specific drug effect of the new PPI paradigm.

\section{Conclusion}

In conclusion, this study developed a novel PPI paradigm firstly for human subjects. The modified PPI paradigm investigated not only sensorimotor gating but also attention function and correlated with symptom severity. The novel paradigm might be suitable for clinical study and application.

\begin{abstract}
Abbreviations
ATT: Attention score; AUC: Area under the ROC curve; DEM: Delayed memory score; EMG: Electromyography; HC: Healthy controls; IMM: Immediate memory score;"; INT-C: Color interference time; INT-W: Word interference time.; LAN: Language score; PANSS: Positive and negative syndrome scale; PPI: Prepulse inhibition; PSC-PPI: Perceived spatial co-location prepulse inhibition; PSS-PPI: Perceived spatial separation-induced prepulse inhibition; RBANS: Repeatable Battery for the Assessment of Neuropsychological Status; SCID: The structured clinical interview for DSM-IV; SZ: Schizophrenia patients; TOT: Total cognitive function score; VC: Visuospatial/constructional score
\end{abstract}

\section{Acknowledgements}

The authors would like to thank Fu-Chun Zhou M.D., Ph.D., Xian-Bin Li M.D., Ph.D. and Ming Lei Ph.D. for their assistance with the revision of this manuscript. The authors would also like to thank all individuals who agreed to serve as research subjects, and members of our research group for assistance in data collection.

\section{Funding}

This study was funded by the National Natural Science Foundation of China (81471365), Beijing Municipal Science \& Tech Commission (Z161 100002616017), Beijing Institute for Brain Disorders (PXM2015_014226_000051), Beijing Municipal Administration of Hospitals (ZYLX201403 and 2011-2012-02).

\section{Availability of data and materials}

Data are available from the first and the corresponding authors.

\section{Authors' contributions}

NY and QT contributed equally to the manuscript. LL and CW designed the experimental conception of the study. Acquisition of data was carried out by NY, QT, YF, LZ and QB. NY and QT oversaw the data collection. Statistical analysis was performed by NY and QT. Funding was obtained by LL and CW. NY and QT wrote the first draft of the manuscript with significant support from other authors. All authors read and approved the final version of this manuscript.

\section{Competing interests}

The authors declare that they have no competing interests.

\section{Consent for publication}

Not applicable.

\section{Ethics approval and consent to participate}

The study protocols were approved by the clinical research ethics committees of Beijing Anding Hospital, Capital Medical University, reference number 2015127FS-2, extension date Sept 27, 2016, and was performed in accordance with the ICH-GCP, and related regulation and law of China. The written informed consent was obtained from all the participants before enrollment. All participants were assessed by psychiatrists and medical doctors specifically trained in the study's protocol. Before signing, the assessor went through the consent form with the participant and his (her) legal guardian, particularly ensuring that he or she was fully understood the nature, purpose and the procedures of the research study they were participating in, and what their consent meant their right to opt-out the study at any time without consequences. These criteria for obtaining informed consent were approved by the clinical research ethics committees of Beijing Anding Hospital, Capital Medical University, ref. \# 2015127FS-2, extension date Sept 27, 2016.

\section{Publisher's Note}

Springer Nature remains neutral with regard to jurisdictional claims in published maps and institutional affiliations.

\section{Author details}

'Department of Psychiatry, Beijing Anding Hospital, Capital Medical University, No.5 Ankang Lane, Dewai Avenue, Xicheng District, Beijing 100088, China. ${ }^{2}$ Beijing Key Laboratory of Mental Disorders, No.5 Ankang Lane, Dewai Avenue, Xicheng District, Beijing 100088, China. ${ }^{3}$ Beijing Institute for Brain Disorders Center of Schizophrenia, No.5 Ankang Lane, Dewai Avenue, Xicheng District, Beijing 100088, China. ${ }^{4}$ Department of Psychology, Peking University, Beijing 100871, China. ${ }^{5}$ Key Laboratory on Machine Perception (Ministry of Education), Beijing 100871, China. ${ }^{6}$ McGovern Institute for Brain Research, Beijing 100871, China.

Received: 27 December 2016 Accepted: 18 March 2017 Published online: 11 April 2017

\section{References}

1. Adler LE, Pachtman E, Franks R, Pecevich M, Waldo M, Freedman R. Neurophysiological evidence for a defect in neuronal mechanisms involved in sensory gating in schizophrenia. Biol Psychiatry. 1982;17(6):639-654.

2. Callaway E, Naghdi S. An information processing model for schizophrenia. Arch Gen Psychiatry. 1982;39(3):339-47.

3. Swerdlow NR, Braff DL, Taaid N, Geyer MA. Assessing the validity of an animal model of deficient sensorimotor gating in schizophrenic patients. Arch Gen Psychiatry. 1994;51(2):139-54.

4. Clementz BA, Geyer MA, Braff DL. Poor P50 suppression among schizophrenia patients and their first-degree biological relatives. Am J Psychiatr. 1998;155(12):1691-4.

5. Hoffman HS, Ison JR. Reflex modification in the domain of startle: I. Some empirical findings and their implications for how the nervous system processes sensory input. Psychol Rev. 1980;87(2):175.

6. Kumari V, Das M, Zachariah E, Ettinger U, Sharma T. Reduced prepulse inhibition in unaffected siblings of schizophrenia patients. Psychophysiology. 2005;42(5):588-94.

7. Braff DL, Freedman R, Schork NJ, Gottesman II. Deconstructing schizophrenia: an overview of the use of endophenotypes in order to understand a complex disorder. Schizophr Bull. 2007;33(1):21-32.

8. Greenwood TA, Braff DL, Light GA, Cadenhead KS, Calkins ME, Dobie DJ, Freedman R, Green MF, Gur RE, Gur RC. Initial heritability analyses of endophenotypic measures for schizophrenia: the consortium on the genetics of schizophrenia. Arch Gen Psychiatry. 2007;64(11):1242-50.

9. Heekeren K, Meincke U, Geyer MA, Gouzoulis-Mayfrank E. Attentional modulation of prepulse inhibition: a new startle paradigm. Neuropsychobiology. 2004;49(2):88-93. 
10. Thorne GL, Dawson ME, Schell AM. Attention and prepulse inhibition: the effects of task-relevant, irrelevant, and no-task conditions. Int J Psychophysiol. 2005;56(2):121-8.

11. Cornwell BR, Echiverri AM, Covington MF, Grillon C. Modality-specific attention under imminent but not remote threat of shock evidence from differential prepulse inhibition of startle. Psychol Sci. 2008;19(6):615-22.

12. Hazlett EA, Romero MJ, Haznedar MM, New AS, Goldstein KE, Newmark RE, Siever $L$, Buchsbaum MS. Deficient attentional modulation of startle eyeblink is associated with symptom severity in the schizophrenia spectrum. Schizophr Res. 2007;93(1):288-95.

13. Dawson ME, Schell AM, Hazlett EA, Nuechterlein KH, Filion DL. On the clinical and cognitive meaning of impaired sensorimotor gating in schizophrenia. Psychiatry Res. 2000;96(3):187-97.

14. Ashare RL, Hawk LW, Mazzullo RJ. Motivated attention: Incentive effects on attentional modification of prepulse inhibition. Psychophysiology. 2007; 44(6):839-45.

15. Swerdlow NR, Geyer MA, Blumenthal TD, Hartman PL. Effects of discrete acoustic prestimuli on perceived intensity and behavioral responses to startling acoustic and tactile stimuli. Psychobiology. 1999;27(4):547-56.

16. Du Y, Wu X, Li L. Emotional learning enhances stimulus-specific top-down modulation of sensorimotor gating in socially reared rats but not isolationreared rats. Behav Brain Res. 2010;206(2):192-201.

17. Li L, Qi JG, He Y, Alain C, Schneider BA. Attribute capture in the precedence effect for long-duration noise sounds. Hear Res. 2005;202(1):235-47.

18. Li L, Daneman M, Qi JG, Schneider BA. Does the information content of an irrelevant source differentially affect spoken word recognition in younger and older adults? J Exp Psychol Hum Percept Perform. 2004;30(6):1077-91.

19. Huang Y, Huang Q, Chen X, Qu T, Wu X, Li L. Perceptual integration between target speech and target-speech reflection reduces masking for target-speech recognition in younger adults and older adults. Hear Res. 2008;244(1):51-65

20. Wu X, Wang C, Chen J, Qu H, Li W, Wu Y, Schneider BA, Li L. The effect of perceived spatial separation on informational masking of Chinese speech. Hear Res. 2005;199(1):1-10.

21. Lei M, Luo L, Qu T, Jia H, Li L. Perceived location specificity in perceptual separation-induced but not fear conditioning-induced enhancement of prepulse inhibition in rats. Behav Brain Res. 2014;269:87-94.

22. Braff DL, Swerdlow NR, Geyer MA. Symptom correlates of prepulse inhibition deficits in male schizophrenic patients. American Journal of Psychiatry. 1999;156(4):596-602.

23. Leumann L, Feldon J, Vollenweider FX, Ludewig K. Effects of typical and atypical antipsychotics on prepulse inhibition and latent inhibition in chronic schizophrenia. Biol Psychiatry. 2002;52(7):729-39.

24. Notredame CE, Pins D, Deneve $S$, Jardri R. What visual illusions teach us about schizophrenia. Front Integr Neurosci. 2014;8:63

25. Fletcher PC, Frith CD. Perceiving is believing: a Bayesian approach to explaining the positive symptoms of schizophrenia. Nat Rev Neurosci. 2009;10(1):48-58.

26. Swerdlow NR, Light GA, Cadenhead KS, Sprock J, Hsieh MH, Braff DL. Startle gating deficits in a large cohort of patients with schizophrenia: relationship to medications, symptoms, neurocognition, and level of function. Arch Gen Psychiatry. 2006;63(12):1325-35.

27. Duncan E, Szilagyi S, Schwartz M, Kunzova A, Negi S, Efferen T, Peselow E, Chakravorty S, Stephanides M, Harmon J. Prepulse inhibition of acoustic startle in subjects with schizophrenia treated with olanzapine or haloperidol. Psychiatry Res. 2003;120(1):1-12.

28. Kumari V, Soni W, Sharma T. Normalization of information processing deficits in schizophrenia with clozapine. Am J Psychiatr. 1999;156(7):1046-51.

29. Weike Al, Bauer U, Hamm AO. Effective neuroleptic medication removes prepulse inhibition deficits in schizophrenia patients. Biol Psychiatry. 2000:47(1):61-70

30. Meincke U, Mörth D, Voß T, Thelen B, Geyer MA. Gouzoulis-Mayfrank E: Prepulse inhibition of the acoustically evoked startle reflex in patients with an acute schizophrenic psychosis-a longitudinal study. Eur Arch Psychiatry Clin Neurosci. 2004;254(6):415-21.

31. Fioravanti M, Carlone O, Vitale B, Cinti ME, Clare L. A meta-analysis of cognitive deficits in adults with a diagnosis of schizophrenia. Neuropsychol Rev. 2005;15(2):73-95.

32. Dickinson D, Ramsey ME, Gold JM. Overlooking the obvious: a meta-analytic comparison of digit symbol coding tasks and other cognitive measures in schizophrenia. Arch Gen Psychiatry. 2007;64(5):532-42.
33. Oliveras I, Rio-Alamos C, Canete T, Blazquez G, Martinez-Membrives E, Giorgi O, Corda MG, Tobena A, Fernandez-Teruel A. Prepulse inhibition predicts spatial working memory performance in the inbred Roman high- and low-avoidance rats and in genetically heterogeneous $\mathrm{NIH}$-HS rats: relevance for studying pre-attentive and cognitive anomalies in schizophrenia. Front Behav Neurosci. 2015;9:213.

34. Esnal A, Sánchez-González A, Río-Álamos C, Oliveras I, Cañete T, Blázquez G, Tobeña A, Fernández-Teruel A. Prepulse inhibition and latent inhibition deficits in Roman high-avoidance vs. Roman low-avoidance rats: Modeling schizophrenia-related features. Physiol Behav. 2016;163:267-73.

35. Dalmaso M, Galfano G, Tarqui L, Forti B, Castelli L. Is social attention impaired in schizophrenia? Gaze, but not pointing gestures, is associated with spatial attention deficits. Neuropsychology. 2013;27(5):608.

36. He Y, Zhang M. The positive and negative syndrome scale (PANSS) and its application. J Clin Psychiatry. 1997;7(6):353-5.

37. Wang J, Li C, Cheng Y, Yi Z, Long B, Wang J. Reliability and validity of repeatable battery for the assessment of neuropsychological status (RBANS) in schizophrenic patients: a preliminary study. Shanghai Arch Psychiat. 2009; 21:265-8.

38. Wang X, Ren Y, He J, Zhou D. Evaluation of Cognitive Functions and Its Corelation with Psychiatric Symptoms in Patients with Schizophrenia [J]. J Capital Med Univ. 2008;29(4):423-7.

39. Team RC: R: A language and environment for statistical computing. R Foundation for Statistical Computing, Vienna, Austria. 2013. In.: ISBN 3900051-07-0; 2014

40. Braff DL, Geyer MA, Swerdlow NR. Human studies of prepulse inhibition of startle: normal subjects, patient groups, and pharmacological studies. Psychopharmacology. 2001;156(2-3):234-58.

41. Opler MG, Yang LH, Caleo S, Alberti P. Statistical validation of the criteria for symptom remission in schizophrenia: preliminary findings. BMC psychiatry. 2007;7(1):35

42. Braff DL, Geyer MA, Light GA, Sprock J, Perry W, Cadenhead KS, Swerdlow NR. Impact of prepulse characteristics on the detection of sensorimotor gating deficits in schizophrenia. Schizophr Res. 2001;49(1):171-8.

43. Dawson ME, Hazlett EA, Filion DL, Nuechterlein KH, Schell AM. Attention and schizophrenia: impaired modulation of the startle reflex. J Abnorm Psychol. 1993;102(4):633-41.

44. Böhmelt AH, Schell AM, Dawson ME. Attentional modulation of short-and long-lead-interval modification of the acoustic startle eyeblink response: comparing auditory and visual prestimuli. Int J Psychophysiol. 1999;32(3): 239-50.

45. Tang $X$, Wu J, Shen $Y$. The interactions of multisensory integration with endogenous and exogenous attention. Neurosci Biobehav Rev. 2016;61: 208-24.

46. Mathalon DH, Heinks T, Ford JM. Selective attention in schizophrenia: sparing and loss of executive control. Am J Psychiatr. 2004;161(5):872-81.

47. Braff DL. Information processing and attention dysfunctions in schizophrenia. Schizophr Bull. 1993;19(2):233-59.

48. Ott S, Roberts S, Rock D, Allen J, Erlenmeyer-Kimling L. Positive and negative thought disorder and psychopathology in childhood among subjects with adulthood schizophrenia. Schizophr Res. 2002;58(2):231-9.

49. Schultz SK, Miller DD, Oliver SE, Arndt S, Flaum M, Andreasen NC. The life course of schizophrenia: age and symptom dimensions. Schizophr Res. 1997;23(1):15-23.

50. Jardri R, Deneve S. Circular inferences in schizophrenia. Brain. 2013;136(Pt 11):3227-41.

51. Dima D, Dietrich DE, Dillo W, Emrich HM. Impaired top-down processes in schizophrenia: a DCM study of ERPs. Neurolmage. 2010;52(3):824-32.

52. Schmack K, Gomez-Carrillo de Castro A, Rothkirch M, Sekutowicz M, Rossler H, Haynes JD, Heinz A, Petrovic P, Sterzer P. Delusions and the Role of Beliefs in Perceptual Inference. J Neurosci. 2013;33(34): 13701-12.

53. Rabin RA, Sacco KA, George TP. Correlation of prepulse inhibition and Wisconsin Card Sorting Test in schizophrenia and controls: effects of smoking status. Schizophr Res. 2009;114(1):91-7.

54. Laurenson C, Gorwood P, Orsat M, Lhuillier J-P, Le Gall D, Richard-Devantoy S. Cognitive control and schizophrenia: The greatest reliability of the Stroop task. Psychiatry Res. 2015;227(1):10-6.

55. Bitsios P, Giakoumaki SG. Relationship of prepulse inhibition of the startle reflex to attentional and executive mechanisms in man. Int J Psychophysiol. 2005;55(2):229-41. 
56. Gigaux J, Le Gall D, Jollant F, Lhuillier J, Richard-Devantoy S. Cognitive inhibition and quality of life in schizophrenia: a pilot study. Schizophr Res. 2013;143(2):297-300.

57. Jones C, Watson D, Fone K. Animal models of schizophrenia Br J Pharmacol. 2011;164(4):1162-94.

58. Jovanovic T, Szilagyi S, Chakravorty S, Fiallos AM, Lewison BJ, Parwani A, Schwartz MP, Gonzenbach S, Rotrosen JP, Duncan EJ. Menstrual cycle phase effects on prepulse inhibition of acoustic startle. Psychophysiology. 2004; 41(3):401-6.

59. Schächinger H, Müller BU, Strobel W, Langewitz W, Ritz R. Midazolam effects on prepulse inhibition of the acoustic blink reflex. Br J Clin Pharmacol. 1999;47(4):421-6.

Submit your next manuscript to BioMed Central and we will help you at every step:

- We accept pre-submission inquiries

- Our selector tool helps you to find the most relevant journal

- We provide round the clock customer support

- Convenient online submission

- Thorough peer review

- Inclusion in PubMed and all major indexing services

- Maximum visibility for your research

Submit your manuscript at www.biomedcentral.com/submit
Biomed Central 